\title{
Curie Intensity Score
}

National Cancer Institute

\section{Source}

National Cancer Institute. Curie Intensity Score. NCI Thesaurus. Code C133468.

A score assigned to a Curie body segment to indicate the strength of 123I-mIBG uptake. 